\title{
O sentido e o lugar do texto filosófico nas aulas de filosofia do Ensino Médio
}

\author{
Wilson José Vieira' \\ Geraldo Balduíno Horn²
}

\begin{abstract}
Resumo
O artigo mostra a importância do uso do texto de Filosofia nas aulas de Filosofia do Ensino Médio. Os textos estão presentes nas salas de aula, mas nem sempre a formação do professor e as condições de trabalho lhe possibilitam utilizar o texto de maneira efetiva. A utilização do texto de filosofia de forma dinâmica, significativa e articulada à realidade cotidiana do estudante ainda é um desafio a ser enfrentado por maior parte dos professores. Como chegar às questões filosóficas de forma significativa e como desenvolver o "filosofar" com os estudantes e não apenas "ler" o texto de filosofia? Como encontrar o equilíbrio no uso do texto de Filosofia e não desenvolver no Ensino Médio uma espécie de propedêutico do curso de graduação em Filosofia? Essas são algumas das questões que serão abordadas no percurso desse artigo.
\end{abstract}

Palavras-chave: Ensino de Filosofia; Textos Clássicos de Filosofia; Ensino Médio; Metodologia de Ensino

\section{Meaning and place of philosophical text in high school philosophy classes}

\begin{abstract}
The article shows the importance of using Philosophy texts in high school philosophy classes. The texts are present in the classroom, but not always the teacher training and the working conditions enable him/her to use the text effectively. The use of philosophy texts in a dynamic and significant way, articulated to student's daily reality, is still a challenge to be faced by most teachers. How can one come to the philosophical issues in a meaningful way and how to develop the "philosophize" with students and not just "read" the philosophy texts? How to find the balance in the use of Philosophy texts and do not develop in high school a kind of introductory undergraduate course in Philosophy? These are some of the questions that will be approached in the course of this article.
\end{abstract}

Keywords: Teaching Philosophy; Classical Texts of Philosophy; High School; Teaching Methodology

\footnotetext{
1 Licenciado em Filosofia, Professor de Filosofia do Colégio Estadual do Paraná (NRE de Curitiba) e Doutorando em Educação no PPGE/UFPR. E-mail: wilsonjosevieira@yahoo.com.br. 2 Doutor em educação e Professor do Departamento de Teoria e Prática de Ensino do PPGE/UFPR. Coordenador do NESEF/UFPR. E-mail: gbalduino.ufpr@gmail.com.
} 


\section{Introdução}

A presença da Filosofia no Ensino Médio enquanto disciplina escolar traz à tona uma série de questões extremamente importantes relativas ao seu ensino. Vive-se, portanto, por conta do tempo em que esteve excluída, por mais de duas décadas, um momento de defesa da disciplina, de sua consolidação no currículo escolar e, principalmente, de legitimação perante a sociedade brasileira³.

Os principais pesquisadores 4 , que tratam do ensino de Filosofia, afirmam que as aulas de filosofia devem passar de alguma forma e em algum momento, pelo texto filosófico. Filosofar é, conforme afirma Severino (2009, p. 26), "[...] uma grande experiência coletiva, como, de resto, o é toda cultura humana." O diálogo com a tradição filosófica, com os pensadores das diferentes épocas e lugares permite a indagação, a reflexão e a compreensão de nossa realidade atual. Só posso pensar pensando e o pensar envolve recuperar aquilo que já foi pensado. Quanto a este aspecto, ou seja, o da presença do texto de Filosofia em sala de aula, não há grandes discordâncias entre os teóricos citados. A divergência entre eles está localizada no modo como essa apropriação será realizada, nos critérios e na mediação docente.

A questão relativa ao lugar do texto de Filosofia é bastante controversa e polêmica. Seria o texto filosófico o lugar onde se encontra a Filosofia? Onde estariam os problemas filosóficos? Se a pretensão da Filosofia é a compreensão da realidade atual, por que ir aos antigos, ou seja, por que sempre estamos com o "pé" no passado? Não seria mais pertinente o trabalho apenas com textos de jornais,

\footnotetext{
3/mportante salientar que a obrigatoriedade da filosofia, sua inserção no currículo ao lado das demais disciplinas não garante um efetivo ensino de filosofia. Existem grandes desafios a serem enfrentados e os principais estão relacionados aos pressupostos metodológicos, aos conteúdos a serem ensinados e à avaliação. É preciso "[...] pensar esta disciplina viabilizando seu espaço próprio, ou seja, inventando um espaço para ela. Pode-se dizer que ela tem um espaço legal, mas que não é legítimo, pois não conseguiu ainda legitimar esse espaço na prática escolar brasileira." Segundo o Guia de Livros Didáticos (201 1, p. 08) "[...] a conquista deste espaço traz a responsabilidade para qualificá-lo e estruturá-lo da forma mais adequada às necessidades de formação dos jovens. Estes primeiros anos de consolidação do ensino de filosofia merecem um cuidado muito especial por parte de todos os atores neste envolvidos. Trata-se aqui, basicamente, de reiniciar a construção de uma tradição de didática da filosofia e da definição de um perfil geral de trabalho que esteja à altura dos desafios de sua história e dimensão atual." (HORN, 2002, p. 197).

4 SEVERINO (2009), GHEDIN (2009), CUNHA (2009), HORN (2010), OLIVEIRA (2004), COSSUTA (2001), FOLSCHEID (2006), NUNES (2010), PORTA (2007), RODRIGO (2009).
} 
revistas, com vídeos, enfim com elementos mais próximos dos estudantes? Não seria mais adequado o trabalho com comentadores? "[...] Por que ler os clássicos em vez de concentrar-nos em leituras que nos façam entender mais a fundo o nosso tempo? [...]" (CALVINO, 1993, p.14). Não seriam os textos de Filosofia muito complicados, difíceis, complexos aos estudantes de Ensino Médio? Tal perspectiva não geraria, por conta das deficiências educacionais de professores e estudantes, um afastamento do filosofar?

\section{Ensinar filosofia a partir do texto filosófico}

A leitura e a escrita são elementos essenciais ao processo de ensino aprendizagem, ao processo de construção do conhecimento. Educação é comunicação e a leitura e a escrita são formas destacadas de comunicação. Assim, no que tange à atividade filosófica em sala de aula, a leitura e a escrita são mediações fundamentais para o desenvolvimento do modo filosófico de pensar.

A escrita, representação da oralidade por meio de signos, é possibilidade de manutenção da memória diante das mudanças temporais. De acordo com Severino (2009) é a escrita

[...] uma das formas privilegiadas da construção do acervo cultural da humanidade, da cultura como acervo de significações produzidas e acumuladas pela espécie, dos sistemas simbólicos que mais têm capacidade de guardar, sinteticamente, volumes maiores de saberes, de experiências vividas, de significados que, sem ela, perderiam-se ao longo da passagem corrosiva do tempo. (SEVERINO, 2009, p. 6).

Ler e escrever são atividades e instrumentos extremamente importantes, essenciais para o processo reflexivo, e tais habilidades não são atingidas de maneira inata: aprende-se a ler lendo e a escrever, escrevendo. Ações dessa natureza devem ser destacadas no ensino de filosofia, pois o aprendizado da leitura e escrita e sua prática constante significam "aprender a pensar melhor" (GHEDIN, 2009, p. 155).

Esclareça-se que a Filosofia não tem a tarefa de ensinar a ler e a escrever, mas precisa usar das mediações da leitura e da escrita, [...] como uma modalidade de desenvolvimento do pensamento dos 
alunos, como forma de ampliar seu universo interpretativo, permitindo que elaborem sentidos para o conteúdo filosófico mediante a construção de significados (GHEDIN, 2009, p. 160).

O trabalho com a leitura e a escrita é atividade essencial à formação do estudante, responsabilidade, pois, de todas as disciplinas escolares, uma vez que o exercício da cidadania requisita o domínio da língua também nesses dois níveis. A Filosofia na escola pode significar o espaço de experiência filosófica, espaço de provocação do pensamento original, da busca, da compreensão, da imaginação, da análise e do contato com os conceitos filosóficos.

Trata-se, então, de levar esses adolescentes a experienciarem essa atividade reflexiva de compartilhamento desse processo de construção de conceitos e valores, experiência eminentemente pessoal e subjetivada, mas que precisa ser suscitada, alimentada, sustentada, provocada, instigada. Eis aí o desafio didático com que nos deparamos (SEVERINO, 2004, p.108).

Ao deparar-se com problemas5, e esses problemas não estão "[...] prontos, esperando simplesmente que o professor os tome [...]" (PORTA, 2007, p. 26), por meio da leitura dos textos filosóficos, espera-se que o estudante possa pensar, discutir, argumentar e que, nesse processo, crie e recrie para si os conceitos filosóficos. O trabalho com o texto filosófico clássico, pois, caracteriza-se como atividade fundamental para o exercício de sua própria experiência filosófica.

Os textos filosóficos são essenciais para a compreensão do mundo no qual estamos inseridos, da "cultura'ocidental7". Pois, conforme afirma Roberto Gomes

\footnotetext{
5 Segundo Porta (2007, p. 15), um dos grandes empecilhos quanto ao entendimento da filosofia é o de não se entender o "problema" tratado por esta ou aquela filosofia. "[...] a compreensão do problema deve constituir o núcleo essencial, o eixo, tanto do ensino quanto da aprendizagem da filosofia. Não é possível 'entender' filosofia se não se entende 'o problema' abordado por um filósofo."

6 Gramsci no artigo Socialismo e Cultura, escrito em 29 de janeiro de 1916 e publicado no jornal operário II grido del popolo, procura articular a relação existente entre socialismo e cultura. Neste artigo procura, assim como em muitos outros, formar politicamente a classe operária. Gramsci ao aproximar dois fragmentos, de dois pensadores, - Novalis e Vico estabelece os princípios e limites para uma compreensão do conceito de cultura em relação ao socialismo. Para o filósofo italiano a cultura não é um saber enciclopédico, o homem não deve ser visto como o receptáculo de dados brutos a serem classificados pelo cérebro e podendo posteriormente mediante algum estímulo externo responder a cada questão concreta. Esta compreensão é prejudicial principalmente ao proletariado, pois não possibilita a compreensão do valor histórico, da compreensão da própria vida, dos direitos e
} 
(2008, p. 21), "Sempre que uma razão se expressa, inventa Filosofia. O que chamamos de Filosofia grega nada mais é do que o streap-tease cultural que a Razão grega realizou de si mesma". Assim, os textos clássicos de filosofia possibilitam o diálogo com pensadores que nos precederam, com a tradição filosófica.

Exceto no caso de um gênio capaz de reinventar tudo pelas próprias forças, a filosofia não escapa a essa regra comum da cultura que impõe a cada um apoiar-se nos outros para se alimentar e crescer. Desde a aprendizagem da língua materna, a educação se faz por uma retomada de herança. Nesse sentido, todo leitor comporta-se normalmente como vampiro. Se você vier a ser filósofo, será por sua vez vampirizado. Essa é a lei da espécie (FOLSCHEID e WUNENBURGER, 2006, p. 06-07).

Os textos filosóficos representam a memória da construção filosófica do ocidente ${ }^{8}$ também a leitura e a escrita são as formas de expressão mais estáveis ocupando assim lugar de destaque quando se trata do ensino de filosofia. A relação direta e constante com os textos clássicos de Filosofia é algo necessário, fundamental, pois desenvolver um pensamento pela confrontação de outros pensamentos é o único caminho para que se efetive com qualidade o ensino de filosofia (FOLSHEID e WUNENBURGER, 2006, p. 6).

deveres dos trabalhadores, da crítica a sociedade capitalista e da formação da consciência unitária do proletariado

7 A modernidade, caracterizada por uma concepção eurocêntrica, apropriou-se do conceito de cultura tendo em vista sua afirmação perante outros povos. A ideia de cultura ocidental exprime uma concepção burguesa de cultura, uma compreensão do dominador, daquele que se apropriou do conceito de cultura buscando afirmar uma dada perspectiva de mundo, ela é a expressão de uma determinada sociedade. A burguesia se apropriou do conhecimento produzido historicamente e o interpretou em consonância a seus interesses. O mesmo não se deu com o proletariado que acaba repetindo a ideologia burguesa. Segundo Gramsci (1891-1937) cultura é o "exercício do pensamento, aquisição de ideias gerais, hábito de conectar causa e efeito. [...] todos já são cultos porque todos pensam, todos conectam causas e efeitos. Mas o são empiricamente, primordialmente, não organicamente. Portanto, oscilam, dispersam-se, abrandam-se ou se tornam violentos, intolerantes, briguentos, ao sabor dos acasos e das contingências. Para que se entenda melhor, tenho um conceito socrático de cultura: creio que seja um pensar bem, qualquer coisa que se pense e, portanto, executar bem, qualquer coisa que se faça. $E$, assim como sei que a cultura é, também ela, um conceito básico do socialismo [...]" (SCHELESENER, 2009, p. 279)

8 Quando se reporta a cultura ocidental é preciso considerar que este conceito é a expressão da hegemonia da cultura do ocidente em relação a todas as outras culturas. Assim, em uma perspectiva gramsciana o que tornaria uma cultura com valor universal seria sua integração a cultura europeia. 
O "[...] texto é um conjunto de signos lingüísticos que codificam uma mensagem" (SEVERINO, 2009, p. 09) e que possibilita a comunicação entre pessoas, entre consciências, permitindo acontecer a intersubjetividade. Etimologicamente, a palavra texto (latim: textus) significa narrativa, exposição e está associada à ideia de tecido. Assim, texto significa

[...] a composição de significados por meio de entrelaçamento físico de sinais apropriados. Um conjunto de palavras formando uma frase escrita, por exemplo, constitui um texto, pois há composição de significados, formando nomes, verbos, artigos, etc., e entrelaçamento de sinais, letras, traços fisicamente construídos sobre o papel ou sobre a rocha, o mármore, enfim, qualquer outro suporte de escrita ou de inscrições. Mas também consideraremos texto todo objeto portador de mensagem. Assim existem os textos orais, visuais, auditivos (CUNHA, 2009, p. 52).

Existem diferentes tipos de textos, como os filosóficos, literários, poéticos, históricos, científicos, sagrados e, ressalta-se a afirmação de Cunha (2009, p.53) ao afirmar que:

[...] existem textos especificamente filosóficos,- que são aqueles que tratam de formular questões no fundo irrespondíveis senão pelo debate argumentativo - quanto textos não-filosóficos, que podem receber interpretações filosóficas por associação de sentido de suas expressões ou metáforas com questões somente abordáveis por meio de argumentos. Exemplos desse tipo são letras de música, poemas, literatura e obras de arte.

O que caracteriza um texto clássico de filosofia? Qual ou quais as especificidades de um texto clássico de filosofia?

Os textos, propriamente filosóficos são os consagrados pela tradição, são de filósofos conhecidos da História da Filosofia, como por exemplo, de Platão: A República; Aristóteles: Ética a Nicômaco; Voltaire: Cândido ou o Otimismo; Rousseau: Discurso sobre a origem e os fundamentos da desigualdade entre os homens; Nietzsche: Genealogia da Moral; Wittgenstein: Investigações Filosóficas.

Apesar da existência de diferentes estilos de textos filosóficos (diálogo, tratado, resumo, ensaio, poema, aforismo, confissão, carta etc), podemos observar em todos eles a presença de alguns elementos gerais. O texto filosófico pode ser caracterizado pela busca da universalidade e, para chegar a isto, "[...] deve 
apagar as marcas de sua particularidade, a qual, no entanto, todo olhar dirigido à história atesta com evidência" (COSSUTA, 2001, p. 04). Toda obra filosófica, mesmo quando a perspectiva é singular (existencialismo), nunca "[...] deixa de generalizar seu ponto de vista" (Idem, p. 05). "[...] todo texto filosófico tenta mediatizar a relação do particular ao universal, e o que torna as filosofias contraditórias é o que as aproxima." Ou ainda "[...] toda filosofia deve, implícita ou explicitamente validar sua própria possibilidade enunciativa". (lbidem, p. 05); Nos textos filosóficos, segundo Folscheid e Wunenburger (2006, p.14), "a forma está inteiramente submetida à mensagem a comunicar", ou seja, a estrutura, a mensagem presente no texto está "inteiramente redutível a um pensamento racionalmente conduzido, que se move exclusivamente no universo conceitual." Segundo Porta (2007, p. 52) em um texto de filosofia não se "contam coisas", "notícias", o objetivo "não é transmitir informações", por isso o texto filosófico é sempre "objeto de análise" e não "fonte de informação". É preciso ressaltar que o texto de filosofia possui como característica central a universalidade, e isto é o que torna o texto filosófico sempre atual, porém todo texto foi produzido em um determinado contexto e que sempre carregará as marcas daquele ou daqueles que o construíram.

Para o escritor Ítalo Calvino 10, clássicos "são aqueles livros dos quais, em geral, se ouve dizer: 'Estou relendo...' e nunca 'Estou lendo ...'” (CALVINO, 1993, p. 09). Um texto clássico é aquele que por mais que o tenhamos lido, nunca tem seus sentidos esgotados, sua leitura é sempre uma releitura. E quanto mais maduros e mais experientes formos, maiores serão as possibilidades de

\footnotetext{
9 É possível encontrar as razões do texto apelando apenas para o próprio texto? A perspectiva analítica aponta nessa direção, ou seja, de que a razão para a leitura do texto está no próprio texto. Seria possível ler Marx com a preocupação única da lógica interna de seus textos? Existe um discurso filosófico autônomo, sem um determinado contexto, sem um "inimigo"? Não seria este um dos motivos da atual irrelevância social e política da Filosofia? Segundo Danilo Marcondes e Irley Franco (201 1, p. 24), citando William James Durant, "[...] a filosofia está morta. [...] ninguém mais pensaria hoje em condenar à morte um filósofo por expressar suas ideias, como fizeram com Sócrates e Giordano Bruno, por exemplo, 'não porque os homens tenham se tornado mais sensíveis quanto a matar alguém, mas porque não há nenhuma necessidade de matar os que já estão mortos'".

10ltalo Calvino (1923-1985) nasceu em Cuba e ainda criança foi para a Itália. Fez parte do Partido Comunista, lutou contra o fascismo, é considerado um dos maiores escritores europeus do século XX. Em sua obra Por que ler os clássicos (1993), que reúne os principais ensaios e artigos que escreveu, apresenta um ensaio denominado "Por que ler os clássicos". Neste, cita 14 definições de clássicos e motivos para lê-los.
} 
apreciarmos os elementos que compõem um texto clássico. "[...] as leituras da juventude podem ser pouco profícuas pela impaciência, distração, inexperiência das instruções para o uso, inexperiência da vida" (Idem, p. 10).

Uma das recomendações feitas por Calvino (Ibidem, p. 12) é a de procurar sempre a leitura direta dos textos originais e evitar ao máximo a "possível bibliografia crítica, comentários, interpretações."

\begin{abstract}
A escola e a universidade deveriam servir para fazer entender que nenhum livro que fala de outro livro diz mais sobre o livro em questão; mas fazem de tudo para que se acredite no contrário. Existe uma inversão de valores muito difundida segundo a qual a introdução, o instrumental crítico, a bibliografia são usados como cortina de fumaça para esconder aquilo que o texto tem a dizer e que só pode dizer se 0 deixarmos falar sem intermediários que pretendam saber mais do que ele (CALVINO, 1993, p. 12).
\end{abstract}

O desafio colocado hoje aos que ministram aulas de filosofia no Ensino Médio é saber usar os textos de filosofia com os estudantes, e tratá-los sob o ponto de vista filosófico. Diante das carências, verdadeiras lacunas, na formação dos professores de Filosofia, principalmente quanto ao trabalho com os textos, como transpor os textos aos estudantes? Como desenvolver o "gosto" pela leitura dos textos filosóficos? "Por que ler os clássicos em vez de concentrar-me em leituras que nos façam entender mais a fundo o nosso tempo?" (CALVINO, 1993, p. 14) "Onde encontrar o tempo e a comodidade da mente para ler os clássicos, esmagados que somos pela avalanche de papel impresso da atualidade?" (ldem, p. 14). Afinal, para que ler os clássicos? Para que ler os clássicos de filosofia? Para que servem? "A única razão que se pode apresentar é que ler os clássicos é melhor do que não ler os clássicos" (lbidem, p. 16).

\title{
2. Estudar os textos propriamente filosóficos: para além do estruturalismo
}

Os textos filosóficos, conforme já afirmado, são indispensáveis ao trabalho com a disciplina de filosofia, pois são eles os responsáveis pela transmissão daquilo que foi pensado pelos filósofos, pela transmissão da tradição. O ensino de Filosofia passa de alguma forma, pela leitura e interpretação daquilo que foi produzido 
pelos filósofos, pela tradição. É pela leitura dos clássicos que entramos em contato com os diferentes problemas filosóficos e as diferentes maneiras encontradas pelos filósofos para tratar esses problemas.

Antes de mais nada, todo procedimento filosófico encontra diante de si uma história, um passado. Não poderíamos fazer como se começássemos a filosofar sozinhos e pela primeira vez. Filosofar é, em primeiro lugar, colocar-se em presença de uma filosofia anterior. Entretanto, isso não significa inclinar-se diante de uma tradição, como se festejam os santos; as grandes filosofias são algo bem diferente de obras-primas insuperáveis que suscitariam a veneração e que deveríamos visitar como um museu. Ao contrário de uma fria historiografia, a história da filosofia deve servir para descobrir pensamentos vivos em ação, para encontrar filosofias em ato, através das quais possamos dar a nosso próprio pensamento um suporte, um quadro para orientá-lo. Por isso a prática da filosofia é, antes de mais nada, inseparável de uma freqüentação de textos que devemos aprender a ler, a explicar e a comentar. Por essa prática podemos esperar reconstituir escrupulosamente o trabalho do pensamento de outrem, evitando os estereótipos escolares que simplificam as obras, contornando o obstáculo das palavras e a aparência enganosa das fórmulas prontas, ao mesmo tempo em que situamos as filosofias em itinerários, contextos, sistemas coerentes, que as liberam de todo peso histórico e as elevam à categoria de pensamento vivo e atual (FOLSCHEID, 2006, p. X-XI).

Embora reconheçamos a importância da presença e do uso do texto de filosofia com os estudantes de Ensino Médio, tal questão requer melhor fundamentação, pois se corre muitas vezes o risco de mistificar o texto clássico de filosofia e considerar que a relação com o texto seja "o todo da atividade filosófica", não buscamos limitar o ensino de filosofia

ao reducionismo empobrecedor da "onipotência do texto", que não só faz do trabalho com o texto a modalidade privilegiada da atividade filosófica, mas que tende também a reduzir a esse trabalho [e a entender a partir dele] toda outra forma de atividade filosófica, de tal modo que ela perde sua especificidade e o original de sua oportunidade (PORTA, 2007, p. 95).

Tratar da onipotência do texto da leitura e exegese dos textos de filosofia requer uma breve retomada do ensino de filosofia no Brasil.

Em um primeiro momento a presença do ensino de filosofia ocorreu em função da presença dos jesuítas em terras Tupiniquins. Não se pode desconsiderar a 
influência jesuítica na educação brasileira, porém, com a chegada da missão francesa na década de 1930 e a fundação da Universidade de São Paulo em 1934 ocorrerá a propagação do ensino de filosofia no Brasil (PIMENTA, 2008). A partir disto, identifica-se a instauração de um processo de formação de estudos e pesquisas filosóficas no Brasil, especialmente em São Paulo.

Paulo Eduardo Arantes em seu livro Um Departamento Francês de Ultramar: estudos sobre a formação da cultura filosófica uspiana (1994) faz uma reconstrução histórica da introdução da Filosofia no Brasil e da criação do curso de Filosofia na Universidade de São Paulo (USP). A questão central da obra é a influência da filosofia europeia, principalmente a francesa, na constituição ou estabelecimento da filosofia no Brasil. "Nossa bruxuleante curiosidade filosófica, como é sabido, sempre viveu à mercê das marés ideológicas da metrópole, literalmente a reboque dos vapores da linha da Europa [...]" (ARANTES, 1994, p. 61) Segundo ele ocorreu no Brasil a partir de 1935 a importação de um Departamento Francês de Filosofia, "[...] peça por peça [...] juntamente com as doutrinas consumidas ao acaso dos ventos europeus e dos achados de livraria, a própria usina que as produzia em escala acadêmica." (Idem)

A presença francesa significava o esclarecimento, a redenção da oligarquia burguesa paulista. Nossos "heróis civilizadores" estabeleceram o início da Filosofia no Brasil e principalmente as diretrizes para o ensino de filosofia: "[...] o ensino da filosofia deverá ser principalmente histórico "(Idem p. 71-72)

[...] é inconcebível que se aprenda filosofia - e seria preciso pôr aspas no verbo - sem que os autores sejam lidos, e dans le texte. Outra marca de nascença, ou vício de origem, se anteciparmos o desdobramento desse impulso inicial: história quer dizer aqui simplesmente retorno aos textos eles mesmos, com perdão do compreensível galicismo. Também neste passo das diretrizes fixadas por Maugüé, tal conseqüência escolar era estritamente kantiana, além de reproduzir no plano miúdo da rotina acadêmica (cujo peso afinal era decisivo) um dos mandamentos da filosofia universitária francesa. Se é verdade que não se pode jamais ensinar filosofia a não ser historicamente, como queria Kant, a leitura dos clássicos vem a ser o único meio de aprender filosofar. (ARANTES, 1994, p. 72)

O ensino de Filosofia no Brasil foi instituído sob os preceitos do ensino de Filosofia francês. A aquisição metódica de um senso de compreensão das ideias, de 
se estabelecer critérios, de discernir os bons livros dos ruins e principalmente 0 aprendizado da leitura e exegese dos textos clássicos de Filosofia.

[...] Vem sem dúvida daí - e nem poderia ser de outro modo - nosso apego à interminável ruminação de textos, a ponto de até hoje confundir-se nos meios uspianos filosofia e explicação de texto, provocando de um lado a demagogia da direita, que nestas paragens costumava transpirar 'autenticidade' (OS filisteus da USP não são filósofos, quando muito filólogos esforçados) e pondo, à prova, por outro lado, a paciência da esquerda, sempre inconformada com tamanha assepsia. (ARANTES, 1994, p. 75)

Esta metodologia consistirá no Brasil na metodologia por excelência para o ensino de filosofia. A implementação do modelo francês teve em Martial Gueroult (1891-1976), professor de História da Filosofia na Sorbonne e no Collège de France, sua expressão mais conhecida, porém sua difusão ocorreu em função de um texto introdutório do livro A religião de Platão (Tempo Histórico e Tempo Lógico na Interpretação dos Sistemas Filosóficos) escrito por Victor Goldschmidt (1914-1981). Nesta perspectiva, segundo Pimenta (2008, p. 125) não existiria filosofia sem a história da filosofia, assim estudar filosofia se circunscreveria a "compreensão dos conceitos e da ordem interna do texto filosófico." Na USP a pesquisa em filosofia foi inspirada pela "[...] busca da identificação e da reconstrução da ordem interna ou ordem das razões [...]" (Idem, Ibidem).

Na perspectiva de leitura estruturalista dos textos filosóficos, o texto filosófico é reduzido a uma abordagem filológica, puramente exegética, assim a obra filosófica é tratada como "um ser", algo apartado do mundo, e o trabalho do leitor filósofo seria a de adentrar na obra pela análise textual. Tal perspectiva é muito presente em muitos cursos de Filosofia do Brasil por conta de sua constituição histórica.

Denilson Soares Cordeiro apresentou em 2008 sua tese, cujo título era A formação do discernimento: Jean Maugüe e a gênese de uma experiência filosófica no Brasil, ao programa de Pós-graduação do Departamento de Filosofia da Universidade de São Paulo. Na introdução (p. 11-12) o autor faz referência a um momento inicial de sua formação em filosofia no qual explicita a metodologia de ensino de Filosofia. 
Meu primeiro seminário no curso de Filosofia teve como base um texto de Rudolf Carnap, intitulado "A superação da metafísica pela análise lógica da linguagem", como parte de uma discussão que se estabeleceria com o seminário sobre o texto "O que é metafísica?" de Heidegger. Nossa apresentação procurou refazer o caminho de argumentos e contra-argumentos filosóficos, mas não nos passava despercebido o registro das consequências políticas na divergência de princípios que levaria o Círculo de Viena de Carnap e Schilick para o exílio americano e o filósofo da Floresta Negra a deixar-se levar pelo canto da sereia da onda antisemita. Mas, como recomendavam e exigiam, não convinha tentar falar de História em se tratando Filosofia. (CORDEIRO, 2008, p. 11-12)

Ao se referir a Paulo Arantes e aos procedimentos utilizados nas aulas no curso de filosofia de seu orientador, Cordeiro (2008, p. 13) afirma que o curso começava com a seguinte afirmação: "[...] o que vamos estudar neste semestre vai, com sorte, nos ajudar a ler melhor os cadernos de cultura da imprensa. [...] Mas e os "clássicos" Perguntavam os fiéis do método? E os comentadores?"

Assim em muitos cursos de Filosofia ocorreu e ainda ocorre o debruçamento sobre os textos filosóficos, a leitura estruturalista dos textos, a extrema especialização filosófica, sem relevância social e política, sem presença na imprensa, uma fala para si mesmo, disputas puramente filológicas e herméticas. Dessa maneira, o texto de filosofia precisa ser concebido enquanto instrumento para se pensar e repensar o presente, para que a existência seja problematizada e não para ser simplesmente comentado. Seria possível ler Marx com a preocupação única da lógica interna de seus textos? Existiria uma autonomia do discurso filosófico? Não seria um contrassenso "entrar" no texto filosófico como se ele não tivesse contexto, "adversário", indiferentes a sociedade a qual estamos inseridos? Não seria necessário hoje pensar em uma nova "refuncionalização" do texto de Filosofia? Ou será que tal perspectiva engendraria uma "dogmatização" do estudante de Ensino Médio?

Existem, quanto ao trabalho com os textos de filosofia em sala de aula, três teses. A primeira apresenta a ideia de que apenas é possível ensinar filosofia com o texto filosófico. Tal perspectiva está fundamentada na "etiqueta estruturalista", na leitura estrutural e em uma tendência de sacralização dos textos, própria da academia. A segunda tese é a de que não é necessário, nem possível ensinar 
filosofia no Ensino Médio utilizando o texto como tecnologia central. E esta orientação advém de professores não formados em filosofia e/ou das condições adversas da escola. A terceira possibilidade, que não exclui em absoluto as outras, defende a aproximação do texto filosófico em sala de aula não como a única e exclusiva possibilidade. É possível ensinar filosofia com qualquer texto, porém preferencialmente com o texto filosófico, pois ensinar filosofia sem a presença do texto de filosofia acarretaria afastamento do conteúdo e do método filosófico. (HORN, 2013).

A principal questão é como chegar às questões filosóficas de forma significativa, como desenvolver o "filosofar" com os estudantes e não apenas "ler" o texto de filosofia? Como encontrar o equilíbrio no uso do texto de Filosofia e evitar desenvolver no Ensino Médio uma espécie de propedêutico do curso de graduação em Filosofia? Como desenvolver a experiência do pensar filosófico, sem cair no vazio e ao mesmo tempo sem criar em nossos estudantes uma repulsa pela Filosofia?

\section{Considerações finais}

Do exposto até aqui, pode-se concluir que a aula de Filosofia, em algum momento, deve passar pelo texto clássico de filosofia uma vez que o diálogo com a tradição, com o pensamento pensado, é algo essencial para que ocorra a indagação, a reflexão quanto ao mundo que nos circunda. O texto clássico é clássico por que fala de seu tempo, mas ele pode dizer alguma coisa para o nosso tempo, é nesse sentido que ele é importante, não é para fazer o aluno conhecer de forma abstrata a filosofia, mas para ele adquirir o instrumental para compreender sua realidade, participar de sua realidade.

Observa-se que existem muitas dificuldades no uso do texto clássico e que há um enorme trabalho a ser desenvolvido na busca de superação das mesmas. Afinal, como criar o hábito de leitura se nossos estudantes de escolas públicas, e também particular, de forma geral não possuem o hábito de leitura? E mais, como criar o "gosto" pela leitura dos textos clássicos de filosofia se os estudantes encontram dificuldades até na leitura de artigos de jornal? Em filosofia, a 
apropriação é lenta e se em algum momento isto não ocorrer pode ser que o fundamental não tenha sido atingido. Podemos comparar a leitura dos textos filosóficos à realização de atividade física. Tornar-se um bom atleta demanda tempo, disciplina, empenho, retomada contínua dos exercícios, etc. Se os textos de Filosofia são uma mediação para o pensar, logo apenas com sua "freqüentação", com o contato, com a prática contínua é possível o desenvolvimento de um pensar autônomo, de um filosofar. O avanço, a progressão na leitura dos textos clássicos de filosofia depende fundamentalmente de uma constância, de uma regularidade. Para Folscheid e Wunenburger (2006, p.17) "[...] se os conceitos ignoram largamente o tempo, o tempo permite entrar pouco a pouco nos conceitos. Para ser claro: a iniciação exige duração."

A filosofia, enquanto conjunto de conhecimentos teóricos reúne grande parte dos temas que influenciam a vida de nossos estudantes. Seja no campo de política, da ética, da ciência, seja no campo da arte, os conhecimentos filosóficos determinam, mesmo que inconscientemente, o modo e o sentido segundo o qual as pessoas em geral abordam o mundo e a vida. $O$ grande problema se encontra, contudo, no fato de que as teses, as doutrinas, os argumentos filosóficos se caracterizam por uma validade tácita, isto é, eles determinam as perspectivas dos estudantes sem que estes estejam conscientes disso. Para citar um exemplo, o conceito de liberdade vigente que vige em nossa circunstância histórica é profundamente marcado pelas teorias liberais dos séculos XVII e XVIII. Quando a mídia, os políticos e as pessoas em geral falam sobre a liberdade, suas posições são orientadas pelas discussões realizadas por Locke, Hobbes, Rousseau, etc.; muito embora, na maior parte das vezes, não tenham conhecimento e leitura das obras desses autores. Este paradoxo funda-se no fato de que nossas instituições e nossos comportamentos foram construídos ao longo da história em sintonia com as teorias e os pensamentos dos filósofos. As pessoas educadas num contexto já determinado incorporam perspectivas específicas e, ingenuamente, acreditam que elas são únicas e nunca foram ou serão diferentes do que são. Eis a validade tácita que caracteriza as teses, as doutrinas e os argumentos filosóficos. Além disso, como podemos notar na declaração de Paris, os conhecimentos de Filosofia são 
necessários para a formação plena do cidadão, de forma a torná-lo participativo, consciente e reflexivo.

[...] ação filosófica formando espíritos livres e reflexivos capazes de resistir às diversas formas de propaganda, fanatismo, exclusão e intolerância, contribui para a paz e prepara cada um para assumir suas responsabilidades face às grandes interrogações contemporâneas [...] Consideramos que a atividade filosófica - que não deixa de discutir livremente nenhuma idéia, que se esforça em precisar as definições exatas das noções utilizadas, em verificar a validade dos raciocínios, em examinar com atenção os argumentos dos outros - permite a cada um aprender e pensar por si mesmo [...] (UNESCO, 1995).

Por fim, é importante ressaltar ainda que a prática da leitura de textos da tradição filosófica possibilitará o contato do estudante com o pensamento dos filósofos. Muito embora, possamos encontrar problemas filosóficos no cotidiano, nos filmes, em recortes de jornais, nas poesias e nas músicas etc, é nas obras dos filósofos que residem os problemas e conceitos metodicamente organizados que orientam a atividade filosófica.

\section{Referências bibliográficas}

ARANTES, P. E. Um departamento francês de Ultramar: estudos sobre a formação da cultura filosófica uspiana. Rio de Janeiro: Paz e Terra, 1994.

BRANDÃO, R.A ordem do mundo e o homem: estudos sobre metafísica e moral em Voltaire. 2008. Tese Doutorado, Universidade de São Paulo.

BRASIL. Ministério da Educação. Secretaria de Educação Básica. Guia de Livros Didáticos PNLD 2012: Filosofia. Brasília, 2011.

BRASIL. Lei 11.684, junho de 2008. Inclui a Filosofia e a Sociologia como disciplinas obrigatórias nos currículos do ensino médio. Disponível em: http://www.planalto.gov.br/ccivil_03/_Ato2007-2010/2008/Lei/L11684.htm. Acesso em 06/09/2010.

CALVINO, Í. Por que ler os clássicos. São Paulo: Companhia das Letras, 1993.

CARTOLANO, M. T. P. Filosofia no Ensino de $2^{\circ}$ Grau. São Paulo: Cortez / Autores Associados, 1985.

CERLETTI, A. O ensino de filosofia como problema filosófico. Tradução de: Ingrid Müller Xavier. Belo Horizonte: Autêntica Editora, 2009.

CHAUÍ, M. Prefácio In: PARANÁ. SEED. Antologia de Textos Filosóficos. Curitiba: 2009, p.9-13. 
COMTE-SPONVILLE, A. A Filosofia. Tradução de: Joana Angélica D'Avila Melo. São Paulo: Martins Fontes, 2005.

COMTE-SPONVILLE, A. Uma educação filosófica e outros artigos. Tradução de: Eduardo Brandão. São Paulo: Martins Fontes, 2001.

CORDEIRO, D.S. A formação do discernimento: Jean Maugüé e a gênese de uma experiência filosófica no Brasil. Tese de doutorado realizado pela USP. São Paulo, 2008.

COSSUTA, F. Elementos para a Leitura dos Textos Filosóficos. 2. ed. São Paulo: Martins Fontes, 2001.

CUNHA, J. A. Iniciação à investigação filosófica: um convite ao filosofar. Campinas: Alínea, 2009.

DELEUZE, G.; GUATARRI, F. O que é Filosofia. Rio de Janeiro: Editora 34, 1997.

FAVARETTO, C. F. Prefácio. In: ROCHA, R. P. Ensino de Filosofia e Currículo Ensino de Filosofia e currículo. Petrópolis: Vozes, 2008. p. 09-15.

FOLSCHEID, D.; WUNENBURGER, J.J. Metodologia Filosófica. 3. ed. São Paulo: Martins Fontes, 2006.

GHEDIN, E. Ensino de Filosofia no Ensino Médio. 2. ed. São Paulo: Cortez, 2009.

GOMES, R. Crítica da Razão Tupiniquim. 14. ed. Curitiba: Criar Edições, 2008

GRAMSCI, A. Escritos Políticos. Vol. I Tradução de: COUTINHO, C. N. Rio de Janeiro: Civilização Brasileira, 2004.

HORN, G.B. Ensinar filosofía: pressupostos teóricos e metodológicos. ljuí: Unijuí, 2009.

HORN, G.B.Filosofia, ensino e resistência: construindo um espaço para filosofia no currículo do ensino médio da escola pública paranaense. Caderno de pesquisa: pensamento educacional, Curitiba, v. 2, n. 4, p. 165-180, 09 novembro 2007. Disponível

em:

<http://www.utp.br/Cadernos_de_Pesquisa/pdfs/cad_pesq4/10_filosofia_cp4.pdf>.

Acesso em: 11/07/2011.

HORN, G.B. Por Uma Mediação Praxiológica do Saber Filosófico No Ensino Médio: Análise e Proposição a Partir da Experiência Paranaense. Tese de doutorado realizado pela FEUSP. São Paulo, 2002.

HORN, G.B. Filosofia no ensino. In: KUENZER, A. (org.) Ensino Médio: Construindo uma proposta para aqueles que vivem do Trabalho. São Paulo: Cortez, 2000, p. 193 - 202.

HORN, G.B.; VALESE R. O sentido e o "lugar" do texto filosófico nas aulas de Filosofia no EnsinoMédio. In: NOVAES, J. L. C; AZEVEDO, M.A.O de. (org). Filosofia e sevensino: desafios emergentes. Porto Alegre: Sulina, 2010.

KANT, I. Textos Seletos, 3 ed. Petrópolis, Rio de Janeiro: Vozes, 2005.

MARCONDES, D. É possível ensinar Filosofia? E, se possível, como? In: KOHAN, W.O. (Org.). Filosofia: caminhos para seu ensino. Rio de Janeiro: DP\&A, 2004. 
MARCONDES, D. FRANCO, I. A Filosofia: O que é? Para que serve? Rio de Janeiro: Zahar/PUC-Rio, 2011

MARTINS, M. H. O que é leitura. São Paulo: Brasiliense, 2007.

MENDES, A. A. P. A construção do lugar da filosofia no currículo do ensino médio: análise a partir da compreensão dos professores de filosofia da escolapública paranaense. 163f. Dissertação (Mestrado) - Setor de Educação, Universidade Federal do Paraná, Curitiba, 2008.

NASCIMENTO, M. G. de. S. Voltaire: a razão militante. Col. Logos. São Paulo: Moderna, 1993.

NUNES, B. Ensaios filosóficos. São Paulo: WMF Martins Fontes, 2010.

OLIVEIRA, J. R. O livro didático de filosofia em foco. In: FRIGOTTO, G.; CIAVATTA, M. (Org.). Ensino Médio: ciência, cultura e trabalho. Brasília: MED, SEMTEC, 2004, p. 253 275.

ORLANDI, J. Duas possibilidades de interpretação do problema do círculo da compreensão em Heidegger.103 f. Dissertação (Mestrado em Filosofia), Setor de Filosofia, Universidade Federal do Paraná, Curitiba, 2008.

PARANÁ. SEED. Antologia de Textos Filosóficos. Curitiba, 2009.

PARANÁ. Diretriz Curricular de Filosofia para a Educação Básica, Curitiba. 2008.

PARANÁ. Secretaria de Estado da Educação. Livro Didático Público de Filosofia. 2 ed. Curitiba: SEED-PR, 2007.

PIMENTA, A. História da filosofia e filosofar. Um olhar crítico sobre o método das estruturas de M. Gueroult. Luminaria. Vol. 1, n 9, p. 124-139, 2008.

PORTA, M. A. G. A filosofia a partir de seus problemas. 3. ed. São Paulo: Loyola, 2007.

RODRIGO, L. M. Filosofia em sala de aula: teoria e prática para o ensino médio. Campinas: Autores Associados, 2009.

RODRIGO, L. M. Aprender filosofia ou aprender a filosofar: a propósito da tese kantiana. In: GALLO; S., DANELON; M., CORNELLI, G., (Org.). Ensino de Filosofia: teoria e prática. ljuí: Unijuí, 2004, p. 91-99.

SCHLESENER, A. H. Antonio Gramsci: Filosofia, História e Política. In: PARANÁ. SEED. Antologia de Textos Filosóficos. Curitiba, 2009. p. 258-297.

SEVERINO A. J. O ensino da Filosofia: entre a estrutura e o evento. In: GALLO; S., DANELON; M., CORNELLI, G., (Org.). Ensino de Filosofia: teoria e prática. ljuí: Unijuí, 2004, p. 101-112.

SEVERINO, A. J.Filosofia. São Paulo: Cortez, 2007

SEVERINO, A. J. Como ler um texto de filosofia. 2. ed. São Paulo: Paulus, 2009.

SILVEIRA, R.J.T. Ensino de Filosofia no segundo grau: em busca de um sentido. $612 f$ Dissertação (Mestrado em Educação) Setor de Educação, Universidade Estadual de Campinas, Campinas, 1991 
VIEIRA, W. J. Retrato atual do ensino de filosofía e o uso do texto clássico nas escolas públicas do Paraná. Revista Dialogia, São Paulo, Vol. 13, 2011 , p. 73-98. 